\title{
Phytochemical Screening of Murraya koenigii (L.) Spreng
}

\author{
Pujan N. Pandya ${ }^{1}$, Sanjukta Rajhans ${ }^{2}$, Falguni R. Patel ${ }^{2}$, Archana U. Mankad ${ }^{1 *}$, Rakesh M. Rawal ${ }^{2}$ and Nainesh \\ R. Modi ${ }^{3}$ \\ Department of Botany, Bioinformatics and Climate Change Impacts Management, Gujarat University, Ahmedabad \\ Department of Life Sciences, Gujarat University, Ahmedabad \\ Corresponding Author Email: aumankad@gujaratuniversity.ac.in ${ }^{1 *}$ \\ Authors emailid: pujupandya@gmail.com ${ }^{1}$,sanjuktarajhans@gmail.com², falguniamit1211@gmail.com², \\ nrmodi@ rediffmail.com ${ }^{3}$
}

\begin{abstract}
Murraya koenigii (L.) Spreng., commonly known as curry leaf tree is well known in Ayurvedic medicinal system for its varied pharmacological activities like anticancer activity, antioxidant activity, anti-inflammatory activity, anthelmintic activity, antidiabetic and antimicrobial activity. The leaves of this tree had been commonly used to enhance the flavour in culinary purposes for its specific taste and aroma. It's Stem part is commonly used as datun for oral health care purposes.The secondary metabolites present in the plant are also known for its different pharmacological activities. The present study focuses on preliminary qualitative phytochemical Screening and analysis from the hydroalcoholic extracts of root, stem and leaves part which detected the presence of alkaloids, phenols, flavonoids, terpenoids, steroids and tannins in the prepared hydroalcoholic extracts using Soxhlet extraction method.
\end{abstract}

Keywords: Murraya koenigii (L.) Spreng; Soxhlet extraction; Secondary metabolites; Phytochemical Screening.

\section{INTRODUCTION AND PHARMACOLOGICAL PROPERTIES OF MURRAYA KOENIGII (L.) SPRENG.}

It had been noted by WHO that $80 \%$ of the population in the developing countries rely on plant based natural products for their primary health care needs (Gahlawat DK, et al, 2014). Murraya koenigii (L.) Spreng. plant, a medicinal herb, which is well known in Ayurvedic system of medicine, had been widely used in India and other Asian countries as a spice and condiment in culinary purposes. It had been known to possess a varied range of biological activities too (Bhandari PR, 2012). Murraya koenigii (L.) Spreng. belongs to the plant family Rutaceae and is native to India and also found in various regions of Asian subcontinent (Verma, S, 2018). In the traditional medicinal system, it is widely as a cure in various lifestyle diseases and disorders. It is used as a febrifuge, tonic, antidiabetic, antidiarrheal, anti-obesity and as a flavor enhancer in varied culineries (Kumari B, 2018). Varied mineral elements such as iron, calcium, magnesium, Zinc, Sodium had been found to be present along with varied vitamins such as Vitamin A, Vitamin B1, Vitamin B2, Vitamin B3 and Vitamin $\mathrm{E}$ which suggests that the leaves can be used as a supplement for nutrient scarcity (Igara CE et al., 2016).

Murraya koenigii (L.) Spreng. possess varied pharmacological properties which are as follows:

\section{Antioxidant property}

Maryam Zahin et al. demonstrated that the benzene fraction extract showed the highest content of phenolic compounds as well as showed maximal antioxidant activity in the three experimental assays like DPPH assay, FRAP assay and CUPRAC assays which shows that the exogenous supply of antioxidants in the form of Murraya koenigii (L.) Spreng. bio-actives would further help in quenching the endogenous reactive oxygen species generated in the body (Zahin M. et al, 2013). It had also been found that in the methylene chloride extract of curry leaves the presence of various antioxidant carbazole alkaloids had been found of which the DPPH assay showed the efficacy of the phytochemicals bismurrayafoline E, euchrestine B, mahanine were found to be the highest (Tachibana Yet al, 2001)The essential oils in Murraya koenigii (L.) Spreng leaves and stem had also been found to posses moderate antioxidant potential when studied through DPPH assay experiment (Iqbal Zet al., 2017). A carbazole alkaloid Girinimbine present in the stem bark of Murraya koenigii (L.) Spreng. had also been found to posses antioxidant capacity which could be compared to the antioxidant capacity of alpha tocopherol. It had been also found to exhibit anti tumor activity by the inhibition of the expression of EA-EBV virus in the Raji cells ( Kok YYet al., 2012).

\section{Anti-inflammatory potential}

The methanolic extracts of Murraya koenigii (L.) Spreng. leaves had been found to posses analgesic and antiinflammatory activity in acute inflammation in dose dependent manner when experimented on male albino rats (Gupta Set al, 2010). The carbazole alkaloid, girinimbine had been found to possess anti-cancer and antiinflammatory potential by apoptosis induction in HT-29 colon cancer cells and a dose dependent anti-inflammatory activity by inhibiting the nitric oxide production along with reduction in pro-inflammatory cytokine levels (Iman Vet al, 2017).

\section{Antimicrobial activity}

The compound Murrayamine-J and koeninmbine isolated from the crude $\mathrm{CHCl} 3$ : $\mathrm{MeOH}$ extract of stem and leaves had been found to posses antimicrobial activity against the microorganism Staphylococcus aureus whereas the compounds like girinimbine and 1-hydroxy-7-methoxy-8-(3methylbut-2-en-1-yl)-9H-carbazole-3-carbaldehyde had been found to posses potential anti-microbial activity against the Bacillus cerus (Nalli Yet al., 2018)The chloroform extracts of the roots of plant Murraya koenigii (L.) Spreng. shows 


\section{International Journal of Research in Advent Technology, Vol.7, No.4, April 2019 \\ E-ISSN: 2321-9637 \\ Available online at www.ijrat.org}

inhibitory potential against the microorganisms A. niger, P.aeruginosa and C. albicans at lower concentrations as well (Vats Met al., 2011). Murraya koenigii (L.) Spreng. bark's ethanolic extract had been found to possess antmicrobial activity against the microorganisms S.aureus, whereas the leaf ethanolic extracts showed highest antimicrobial activity against the microorganism $P$. vulgaris (Akula P et al., 2016)

\section{Antidiabetic activity}

The chloroform extract of the leaves of Murraya koenigii (L.) Spreng. had been found to exhibit hypogycemic effect of the alloxan induced diabetes in the rats, which had been due to the protective effects such as preservation of pancreatic cell integrity and showing a decreased oxidative stress in rats (Vijayanand S., 2015). The ethanolic extract of the leaves had been also found to exhibit decreased blood sugar levels in dose dependent manner which also showed a decrease in depression levels in the diabetic patients (Tembhurne SV et al., 2017). The ethanolic extract and the nano-particles found in Murraya koenigii (L.) Spreng. leaves also showed the reduced blood glucose levels in rats (Handayani $\mathrm{R}$ et al, 2017). The carbazole alkaloid mahanimbine, isolated from Murraya koenigii (L.) Spreng. leaves exhibited hypolipidemic and antidiabetic effect in the diabetic rats which shows that the compound can be useful in management of diabetes (Dineshkumar B et al., 2010).

\section{Anticancer activity}

The hydroalcoholic extract of Murraya koenigii (L.) Spreng. leaves had been found to exhibit anti-cancer activity against the breast cancer cells MDA-MB-231 through the proteasome inhibitory activity and induction of apoptosis in vitro. Reduced tumor size had also been observed in mice (Noolu B et al., 2016). Leaf extracts from different study locations had also been found to possess inhibitory potential against the breast cancer cells proving its chemopreventive potentiality (Ghasemzadeh A et al., 2014). The carbazole alkaloids mahanine, murrafoline-I and pyrafoline-D had been found to exhibit cytotoxic activity against the human lekemia cell line HL-60 by the caspase-3 pathway actvation and mitochondrial dysfunction ( Ito Cet al., 2006).

\section{Anthelmintic activity}

The aqueous and ethanolic extracts of Murraya koenigii (L.) Spreng. had been found to exhibit anthelmintic activity against the organism Pheretima posthumaat the highest concentration of $100 \mathrm{mg} / \mathrm{ml}$ (Sharma US et al., 2010). The methanolic extract of Murraya koenigii (L.) Spreng. leaves had been found to posses anthelmintic activty against the Haemonchus contortus worms in the larval motility assay and egg hatch assay (Sujith S et al., 2018).

\section{MATERIALS AND METHODOLOGY \\ 2.1Collection and Preparation of Plant Material for Preparation of Extract}

The root, stem and leaves part of the plant was collected. The collected plant material was washed with distilled water thoroughly and air dried at room temperature. The collected, washed and dried plant materials was ground into powder form using mixture grinder and stored in air tight containers for further experimentation.

\subsection{Extract Preparation Using Soxhlet Apparatus}

10 grams of each sample in powder form was taken for its extract preparation using Soxhlet extraction method (Rajhans Set al., 2019). The sample had been finely packed in the filter paper and kept in the thimble part of the extractor. Solvent system of 70:30, methanol: water, was chosen for extraction and $100 \mathrm{ml}$ of the solvent system was taken in the round bottom flask. The heating mantle, round bottom flask, Soxhlet apparatus and condenser were connected to the running tap water and was assembled for the further extraction. The heat from the heating mantle rose up to the Soxhlet apparatus in form of vapor wherein, after condensation, droplets of the solvent system dripped down from the Soxhlet apparatus where the sample had been kept for extraction from the sample. The siphon tube of apparatus was then filled with the extract which further dripped down to the round bottom flask. This process was repeated again and again until all the necessary materials were extracted from the solid part of the sample into the organic solvent in the round bottom flask (Rajhans S et al., 2019). The extract accumulated in the round bottom flask was brought to normal room temperature and were then filtered using Whatman filter paper number-1 and then transferred and poured into clean petriplates. The prepared hydroalcoholic extracts of roots, stem and leaves were air dried at room temperature in the petriplates. 
International Journal of Research in Advent Technology, Vol.7, No.4, April 2019

E-ISSN: 2321-9637

Available online at www.ijrat.org

2.3Phytochemical Screening of the extracts

Phytochemical screening of the hydroalcoholic extract of

Root, Stem and Leaves parts of Murraya koenigii (L.)

Spreng. had been done which revealed the results in Table

\begin{tabular}{|c|c|c|c|}
\hline & Root & Stem & Leaves \\
\hline \multicolumn{4}{|l|}{ Test for Alkaloids } \\
\hline Mayer's Test & + & + & + \\
\hline Wagner's Test & - & - & - \\
\hline Hager's test & + & + & - \\
\hline Dragendroff's test & + & + & + \\
\hline \multicolumn{4}{|l|}{ Test for phenols } \\
\hline $\mathrm{FeCl}_{3}$ test & + & + & + \\
\hline Lead acetate test & + & + & + \\
\hline \multicolumn{4}{|l|}{ Tests for Flavonoids } \\
\hline Alkaline Reagent Test & + & + & + \\
\hline Ammonia test & + & + & + \\
\hline Lead acetate test & + & + & + \\
\hline \multicolumn{4}{|l|}{ Test for Saponin } \\
\hline Foam Test & - & + & + \\
\hline \multicolumn{4}{|l|}{ Test for Terpenoids } \\
\hline Salkowaski's test & + & + & + \\
\hline \multicolumn{4}{|l|}{ Test for Triterpenoids } \\
\hline Salkowaski's test & + & + & + \\
\hline \multicolumn{4}{|l|}{ Test for Anthraquinone } \\
\hline Borntrager's test & - & - & - \\
\hline \multicolumn{4}{|l|}{ Test for Phlobatannin } \\
\hline Precipitate test & - & - & - \\
\hline \multicolumn{4}{|l|}{ Test for Glycoside } \\
\hline Bromine water test & + & + & + \\
\hline Fehling Test & + & + & + \\
\hline \multicolumn{4}{|l|}{ Test for Coumarin } \\
\hline $\mathrm{NaOH}+$ chloroform test & + & + & + \\
\hline \multicolumn{4}{|l|}{ Test for Steroids } \\
\hline Salkowaski's test & + & + & + \\
\hline \multicolumn{4}{|l|}{ Test for Tannin } \\
\hline Lead acetate test & + & + & + \\
\hline
\end{tabular}

The

Table: 1 Preliminary Phytochemical Screening of Root, stem and Leaves extracts of Murraya koenigii (L.) Spreng. (+ indicates positive results \& - indicates negative results)

phytochemical screening for varied phytoconstituents present in the root, stem and leaves part of the plant had been carried out on the basis of reviewed papers by different authors related to their publications on phytochemical screening. The protocols followed for certain tests were, from the research articles by, Verma, D. \& Shrivastava, K. 2018,L Sophiyamole. et al.,2017, Sasikala M. and Sundaraganapathy R., 2017, A kumar et al 2016, RK Bargah et al 2015, K.Sahira Banu \& L. Cathrine, 2015, S. Pendli et al 2014, S C ugochukwa et al. 2013, S. Sharmila et al., 2013, ME Halilu et al. 2012 and KP Salna et al., 2011.

\section{RESULTS AND DISCUSSION}

\subsection{Extract Preparation for phytochemical analysis}

For phytochemical analysis $50 \mathrm{mg}$ of air dried extracts of root, stem and leaves was taken and dissolved in $50 \mathrm{ml}$ of the hydroalcoholic solvent system

\subsection{Preliminary phytochemical screening}

1.In the screening of root extracts of Murraya koenigii (L.) Spreng. by Vats M., the presence of steroids, alkaloids and flavonoids had been observed with different solvent systems (Vats Met al., 2011)

In a study by Sophiyamole L. it had been observed that in MK leaves, the phenols, flavonoids,tannins, saponins, terpenoids and alkaloids had been found to be present [25]. Vijayvargia P. and Vijayvargia R. carried out the preliminary phytochemical analysis of Murraya koenigii (L.) Spreng. in different solvent systems. Alkaloids, triterpenoids and phytosterols had been found to be present in the stem and leaves part of the Murraya koenigii (L.) Spreng (Vijayvargia P. \& Vijayvergia R., 2016).

Presence of Tannins, alkaloids, steroids, tritepenoids and flavonoids had been found to be present in the Murraya koenigii (L.) Spreng. leaves and twings part's crude ethanolic extract in the phytochemical investigations by Kusuma IW (Kusuma IW et al., 2011).

For the detection of alkaloids, Mayer test, Wagner test, Hager test and Dragendroff test had been performed for the root stem and leaves extract. The Mayer test and 


\section{International Journal of Research in Advent Technology, Vol.7, No.4, April 2019 E-ISSN: 2321-9637 \\ Available online at www.ijrat.org}

Dragendroff test were found to be positive for all the three extracts whereas, the Wagner test had been found to be negative for all extracts. Furthermore Hager test showed negative results for leaves but positive for root and stem extracts. For the detection of phenols $\mathrm{FeCl}_{3}$ test and Lead acetate test showed positive results for all extracts. Alkaline reagent test, ammonia test and lead acetate test for detection of flavonoids showed positive results for all the three extracts. Foam test for saponins showed negative results for roots whereas it showed positive results for stem and leaves. Salkowaski test performed for the detection of steroids, terpenoids and triterpenoids showed positive results for all the three extracts. Test for anthraquinone and Phlobatannin showed negative results for all the three extracts. Bromine water test and Fehling test for glycosides, showed positive results for all the three extracts. The test for coumarin, $\mathrm{NaOH}+$ chloroform test showed positive results for all three sample extracts. The lead acetate test for detection of tannins also showed positive results for all the three sample extracts.

\section{CONCLUSION}

The present study reveals the results of preliminary phytochemical screening from the hydroalcoholic extracts of root, stem and leaves of the Murraya koenigii (L.) Spreng. plant had been found to be rich in phytoconstituents such as alkaloids, phenols, flavonoids, terpenoids, steroids, glycosides, coumarins and tannins. Further In vitro and In silico research on the individual phytochemicals and its extraction can provide more insights into the varied pharmacological roles of different phytochemicals. Computational methods such as machine learning approaches using different algorithms could help in providing the insights into the different activities of diverse phytochemicals.

\section{REFERENCES}

[1] Gahlawat DK, Jakhar S, Dahiya P. (2014):Murraya koenigii (L.) Spreng: an ethnobotanical, phytochemical and pharmacological review. Journal of Pharmacognosy and Phytochemistry, 3(3):109-19.

[2] Bhandari PR. (2012): Curry leaf (Murraya koenigii) or cure leaf: review of its curative properties. Journal of medical nutrition and nutraceuticals, Jul 1;1(2):92.

[3] Verma, S. (2018):Overview study on Murraya Koenigii (Mitha neem) :Rutaceae. Journal of Drug Delivery and Therapeutics, 8(4), 90-92.

[4] Kumari B (2018): Taxonomy and ethnobotany of Murraya koenigii (L.) Spreng: An exotic shrub in Rohilkhand region of Uttar Pradesh. Journal of Medicinal Plants, 6(4):123-5.

[5] Igara CE, Omoboyowa DA, Ahuchaogu AA, Orji NU, Ndukwe MK (2016): Phytochemical and nutritional profile of Murraya Koenigii (Linn) Spreng leaf. Journal of Pharmacognosy and Phytochemistry, 5(5):7.

[6] Zahin M., Aqil, F., Husain, F. M., \& Ahmad, I. (2013): Antioxidant capacity and antimutagenic potential of Murraya koenigii.BioMed research international, 2013.

[7] Tachibana Y, Kikuzaki H, Lajis NH, Nakatani N ( 2001 ): Antioxidative activity of carbazoles from Murraya koenigii leaves. Journal of agricultural and food chemistry,49(11):5589-94.

[8] Iqbal Z, Mehmood HK, Hussain M, Mehmood MH, Choudhry MN (2017):Antioxidant activity of essental oil from the leaves and stems of Murraya koenigii. World Journal of pharmaceutical Research,6(7):267273.

[9] Kok YY, Mooi LY, Ahmad K, Sukari MA, Mat N, Rahmani M, Ali AM (2012): Anti-tumour promoting activity and antioxidant properties of girinimbine isolated from the stem bark of Murraya koenigii S. Molecules, 17(4):4651-60.

[10] Gupta S, George M, Singhal M, Sharma GN, Garg V (2010): Leaves extract of Murraya koenigii linn for anti-inflammatory and analgesic activity in animal models. Journal of advanced pharmaceutical technology \& research, 1(1):68.

[11]Iman V, Mohan S, Abdelwahab SI, Karimian H, Nordin N, Fadaeinasab M, Noordin MI, Noor SM (2017): Anticancer and anti-inflammatory activities of girinimbine isolated from Murraya koenigii. Drug design, development and therapy,11:103.

[12] Nalli Y, Khajuria V, Gupta S, Arora P, Riyaz-UlHassan S, Ahmed Z, Ali A (2018): Four new carbazole alkaloids from Murraya koenigii that display antiinflammatory and anti-microbial activities. Organic \& biomolecular chemistry. ;16(11):1994-1994.

[13] Vats M, Singh H, Sardana S (2011): Phytochemical screening and antimicrobial activity of roots of Murraya koenigii (Linn.) Spreng.(Rutaceae). Brazilian Journal of Microbiology, 42(4):1569-73.

[14] Akula P, Sree AN, Santosh B, Sandeep B, Raviteja KB, Keerthi T (2016): Evaluation of anti-microbial activity of leaf and bark extracts of Murraya koenigii (curry leaves). Journal of Pharmacognosy and Phytochemistry, 5(3):101.

[15] Vijayanand S (2015): Evaluation of Antidiabetic activity of Murraya koenigii on Alloxan Induced Diabetic rats. International Journal of Pharma Sciences and Research, 6:12.

[16] Tembhurne SV , More B and Sakarkar DM (2017): Protective Effect of Murraya koenigii Leaves Extract in Glucose Dysregulation and Its Progression of Depression in Streptozotocin Induced Diabetic Rat. Annals of Pharmacology and Pharmaceutics, 2(13)1069.

[17] Handayani R. Harahap U., Karsono (2017): Hypoglycemic Activity of Nano Particles from Temuru Leaves and Temuru(Murraya koenigii (L.) Spreng.) Leaf Extract on Alloxan Induced rats and Antioxidant Activity International Journal of ChemTech Research,10(2): 108-114.

[18] Dineshkumar B, Mitra A, Mahadevappa M (2010): Antidiabetic and hypolipidemic effects of mahanimbine (carbazole alkaloid) from Murraya koenigii (Rutaceae) leaves. International Journal of Phytomedicine,2(1).

[19] Noolu B, Gogulothu R, Bhat M, Qadri S, Sudhakar Reddy V, Bhanuprakash Reddy G, Ismail A (2016): In vivo inhibition of proteasome activity and tumour growth by Murraya koenigii leaf extract in breast 


\section{International Journal of Research in Advent Technology, Vol.7, No.4, April 2019 \\ E-ISSN: 2321-9637 \\ Available online at www.ijrat.org}

cancer xenografts and by its active flavonoids in breast cancer cells. Anti-Cancer Agents in Medicinal Chemistry (Formerly Current Medicinal ChemistryAnti-Cancer Agents),16(12):1605-1614.

[20] Ghasemzadeh A, Jaafar HZ, Rahmat A, Devarajan T (2014): Evaluation of bioactive compounds, pharmaceutical quality, and anticancer activity of curry leaf (Murraya koenigii L.). Evidence-based complementary and alternative medicine, 2014..

[21] Ito C, Itoigawa M, Nakao K, Murata T, Tsuboi M, Kaneda N, Furukawa H(2006): Induction of apoptosis by carbazole alkaloids isolated from Murraya koenigii. Phytomedicine. 2006 May 9;13(5):359-65.

[22] Sharma US, Sharma UK, Abhishek S, Niranjan S, Singh PJ (2010): In vitro anthelmintic activity of Murraya koenigii Linn. leaves extracts. International journal of pharma and bio sciences.1(3).

[23] Sujith S, Priya MN, Deepa CK, Usha PT (2018): Characterization of the Anthelmintic Activity of Murraya koenigii (Linn.). Pharmacognosy Journal, $10(6 s)$.

[24] Rajhans S, Mankad AU, Pandya HA (2019): Screening Thevetia peruviana (Pers.) K. Schum. for its Bioactive Phytochemicals.International Journal of Research and Analytical Reviews, 6(1);932-935.

[25] Sophiyamole L ,Reshma J K, 3 Prabhachandh SR , Babychan N.(2017). Phytochemical analysis of Murraya Koenigii in Urban and Coastal area. Journal of Emerging Technologies and Innovative Research (JETIR),6(7);267-273.

[26] Sasikala $M^{*}$ and Sundaraganapathy R. (2017) Qualitative Analysis of Alkaloids Exist in the Hydroalcoholic Extract of Ipomoea aquatica for SSK. in Tamil Nadu. International Journal of ChemTech Research,10(7);446-454.

[27] A kumar, Yadav J., Kushwaha A.,Amardeep, Sain A.(2016)In vitro analysis of phytochemicals in anti diabetic plant Murraya koenigii. Asian Journal of Biochemical and pharmaceutical Research6(2);150156.

[28] kumar Bargah R. (2015); Preliminary test of phytochemical screening of crude ethanolic and aqueous extract of Moringa pterygosperma Gaertn. Journal of Pharmacognosy and Phytochemistry. 2015 ;4(1).

[29] Banu KS, Cathrine L (2015); General techniques involved in phytochemical analysis. International Journal of Advanced Research in Chemical Science. 2015;2(4):25-32.

[30] S. Pendli, Talari S., Nemali G.Naik SA(2014); Phytochemical screening of root stem and leaf extracts of rubia cordifolia, L. an important medicinal plant,world journal of pharmacy and pharmaceutical sciences,3(10);826-838.

[31] Verma D. \& ShrivastavaK. (2018); Phytochemical analysis and Anti-bacterial assessment of root extract of Asparagus Racemosus (Shhatavari) found in Ambikapur, Surguja (Chhattisgarh). Indian Journal of Applied Research, 8(6);26-28.

[32] Solomon CU, Arukwe UI, Onuoha I(2013); Preliminary phytochemical screening of different solvent extracts of stem bark and roots of Dennetia tripetala G. Baker. Asian journal of plant science and research. 2013;3(3):10-3.

[33] Sharmila S, Jeyanthi RL ,Paul DM , Md Saduzzaman and Bala1 S.(2013):A Comparative Study on Phytochemical Analysis of Murraya Koenigii and Manilkara Zapota, Research Journal of Pharmaceutical, Biological and Chemical Sciences,4(2);1104-1109.

[34]. Halilu ME, Abubakar A, Garbar MK, Isah AA (2012): Antimicrobial and preliminary phytochemical studies of methanol extract of root bark of Crossopteryx febrifuga (Rubiaceae). Journal of Applied Pharmaceutical Science;2(12):66.

[35] Salna KP, Sreejith K, Uthiralingam M, Mithu AP, John Milton MC, Albin TF(2011): A comparative study of phytochemicals investigation of Andrographis paniculata and Murraya koenigii. Int J Pharm Pharm Sci;3(3):291-2.

[36] Vijayvargia P. \& Vijayvergia R. (2016). Assesment of Phytochemicals and Antioxidant Activity of Murraya koenigii Linn. Int J Pharm Sci Res, May 1;7(5):216367.

[37] Kusuma IW, Kuspradini H, Arung ET, Aryani F, Min YH, Kim JS, Kim YU (2011); Biological activity and phytochemical analysis of three Indonesian medicinal plants, Murraya koenigii, Syzygium polyanthum and Zingiber purpurea. Journal of Acupuncture and Meridian Studies, Mar 1;4(1):75-9. 